\title{
Current prognosis and quality of life following surgical treatment for head and neck squamous cell carcinoma
}

\section{Cristina Hernández-Vila}

Department of Oral and Maxillofacial-Head and Neck Surgery, University Hospital Infanta Cristina, 06080 Badajoz, Spain. Correspondence Author: Dr. Cristina Hernández-Vila, Department of Oral and Maxillofacial Surgery, University Hospital Infanta Cristina, Avenida de Elvas s/n, 06080 Badajoz, Spain. E-mail: cristinahernandezvila@hotmail.es



Dr. Cristina Hernández-Vila, M.D., has studied Medicine in the University of Extremadura until 2009. She passed the public exam to get a position in the Maxillofacial Residency Program of the University Hospital Infanta Cristina in Badajoz, Spain where she was training her surgical skills. Additionally, she made stays overseas to complete her training in head and neck reconstruction, craniofacial surgery and dentofacial deformities. Nowadays she is working as a staff member at the Department of Oral and Maxillofacial Surgery in the University Hospital Infanta Cristina in Badajoz, Spain.

\begin{abstract}
Head and neck squamous cell carcinoma (HNSCC) is one of the most common cancers in the world with a close relation with some risk factor like, tobacco, alcohol consumption and more recently, with human papilloma virus infection. A review of the literature about actual prognosis and quality of life in HNSCC has been done analysing the results of surgical treatment and their impact on the quality of life of patients. Despite the elevated incidence of HNSCC, the survival rate has increased considerably over the last years thanks to the development of new surgical techniques, such as, microvascular reconstruction or transoral robotic surgery and the most accurate adjuvant radiochemotherapy. Even in bad prognosis cases, there are many options to take into account not only with curative expectation, even, keeping in mind the preservation of the quality of life of patients. Due to the improvement of the prognosis, the interest of surgeons has been focused on preserve the aesthetics, functional and psychosocial aspect of patients without a worsening of the main objective which is the curative result. Although prognosis of HNSCC has improved, further studies are necessary to understand the behaviour in every case and determine how the impact on the quality of life can be a useful tool to individualize the therapies.
\end{abstract}

Key words:

Carcinoma; squamous cell of the head and neck; head and neck neoplasms/mortality; quality of life; oral cancer

\begin{tabular}{|l|l|}
\hline \multicolumn{2}{|c|}{ Access this article online } \\
\hline Quick Response Code: & Website: \\
\hline & http://www.parjournal.net \\
\cline { 2 - 3 } & \\
\hline
\end{tabular}

This is an open access article distributed under the terms of the Creative Commons Attribution-NonCommercial-ShareAlike 3.0 License, which allows others to remix, tweak and build upon the work non-commercially, as long as the author is credited and the new creations are licensed under the identical terms.

For reprints contact: service@oaepublish.com

How to cite this article: Hernández-Vila C. Current prognosis and quality of life following surgical treatment for head and neck squamous cell carcinoma. Plast Aesthet Res 2016;3:203-10.

Received: 04-04-2016; Accepted: 27-05-2016

(C) 2016 Plastic and Aesthetic Research | Published by OAE Publishing Inc 


\section{INTRODUCTION}

Squamous cell carcinoma (SCC) is one of the most common malignant neoplasms in the head and neck and the sixth cause of cancer worldwide. Approximately 600,000 cases are diagnosed every year. Although head and neck squamous cell carcinoma (HNSCC) includes salivary glands and paranasal sinuses tumours, their low incidence and different behaviour, have been made them be excluded from this study. ${ }^{[1]}$

There are many risk factors associated to HNSCC, but, alcohol and tobacco consumption are the most important and they are related to the $75 \%$ total tumours. However, recent studies have demonstrated that the connection between the infection by oncogenic virus human papillomavirus (HPV) (specifically the serotype 16) and SCC is an established cause of oropharynx cancer, mainly located in tonsils and base of the tongue. ${ }^{[2,3]}$ Currently, the incidence of HPV-related HNSCC has been increased in the young population.

The survival rate of HNSCC among the last 20 years has increased considerably. The development of new methods of diagnosis, surgical techniques, radiotherapy (RT) and chemotherapy (CMT), are helpful tools that contributed to achieve the best results. ${ }^{[4]}$

During the last decades, head and neck surgeons focused their efforts on morbidity reduction, increased the quality of life and the functional status of the patients. ${ }^{[5]}$ The development of reconstructive surgical techniques such as microvascularized free flaps, led us transfer any kind of tissue (skin, muscle bone, nerves) to the surgical defect after resection.

Treatment choices depend on the neoplasm location, tumour stage and the oncologic free disease survival expectation. Surgery is still the main therapy, most of the time accompanied by postoperative RT. Although, some advanced cases need to be treated with CMT with cetuximab. The overall survival rate varies between $40-60 \%$ after 5 years of treatment. ${ }^{[6]}$

\section{METHODS}

A qualitative review of the literature about actual prognosis and quality of life of oral squamous cell carcinoma has been done analysing the results of surgical treatment and their impact on the quality of life of patients. A bibliographic search on MEDLINE and EMBASE databases, with the key words: "carcinoma, squamous cell of the head and neck"; "head and neck neoplasms/mortality"; "quality of life"; "oral cancer" was conducted. After a manual selection of the abstracts, a total amount of 45 papers were selected from the literature and intensively reviewed.



Figure 1: Infiltrated skin with cervical infection in a recurrent tracheostomized head and neck squamous cell carcinoma patient 


\section{RESULTS CONCERNING PROGNOSIS}

Every year, over 50,000 patients with HNSCC are diagnosed and, approximately 12,000 developed regional disease or distant metastases in United States. Almost $60 \%$ of patients are diagnosed since the first moment as III/IV stage. ${ }^{[7]}$ From $30 \%$ to $50 \%$ of them have locally advanced disease which will develop recurrences and $20-30 \%$ of them will exhibit distant metastases.

The treatment choices for patients with non-resectable metastases are reduced to palliative care therapy, while the main objective of patients with resectable tumours is curative, enhance the overall survival, get a better functional result and palliate the symptoms.

When, the aerodigestive tract is involved can determinate many complications like dysphagia, airway obstruction and speech impediments. The infiltrated skin generates chronic infections, painful and malodorous fistulae [Figure 1]. These are some of the reasons that determine the social and familiar isolation despite the lack on the quality of life (QOL).

The reason of the high incidence of recurrences is still unknown. While the rate of smokers is decreasing, the incidence of patients HPV+ is raising. It seems like cases HPV+ present a low rate of secondary tumours and is not related with the typical cancerization field. Anyway, is well known the connection between the high risk of recurrence and the development of radio-induced tumours with HPV+ cases during a long period of time..$^{[8-10]}$

Recurrences differ from primary tumour because they are typically more infiltrative and multifocal, it is very common to find disseminated tumours outside the radiated field and the surgically area. ${ }^{[1]]}$ Despite the effort to find wide resection margins, the presence of fibrosis and the distortion of the anatomy make us very difficult to get free margins.

\section{PROGNOSIS FACTORS OF RECURRENCES IN HNSCC}

One of the most important criteria is determine the real curative expectation of patients. There are many studies published with ambiguous results because the heterogeneity of the data, the different location sites of the tumours and the therapies included.

\section{Factors depending on the patient}

Comorbidity of the patient is a determinant factor for the prognosis. An excessive loss of weight, high comorbid diseases, low cognitive level, lack of social support, the low quality of life and the continuing alcohol and tobacco abuse are some of the most frequent adverse prognosis factors. ${ }^{[12,13]}$

\section{Factors depending on the tumour}

The most important factor is the stage of the recurrence.
Some studies reveal a significant difference up to 2 years of free disease survival withoutrecurrences (67\% for stage II, $33 \%$ for stage III and $22 \%$ for stage IV). ${ }^{[14]}$ Otherwise, a short interval without recurrences demonstrated an important negative impact factor.

Some studies included more than 500 patients, revealed $20 \%$ of differences of 5 years overall survival with a 9-month interval and considering a short period of free survival disease, probably the most important factor despite the tumour site. ${ }^{[15]}$

Previous computed tomography-scan is considered a poor prognosis factor in patients with recurrences. Many patients showed a worst survival rate after recurrences (5 months mean rate $v s .25$ months). ${ }^{[14]}$ Although the explanation for this result is already unknown, it seems like a good response after induction CMT anticipates a good response in the recurrence area. CMT can detect those patients with more aggressive recurrences. Alternatively, CMT could be a landmark for advances stages where more intense previous therapy is required but with poor prognosis.

\section{Factors depending on tumour location}

Comparing oropharynx with hypopharynx, the larynx tumours developed more early symptoms and could be detected in an early and more treatable stage. The drainage pathways are well established and the lymph dissemination is more predictable. These factors can be observed in cases of recurrences and total laringectomy is already a curative therapy with a 5-year overall survival about $68-70 \%{ }^{[16,17]}$

The favourable prognosis in patients with recurrent laryngeal disease is the reason why many groups propose a more conservative surgical treatment, such as, partial laringectomy performed with transoral laser microsurgery or open partial laryngectomy. Ganly et al. ${ }^{[17]}$ referred that stages rT1-T2 enable to be surgically treated with partial laringectomy have a 5-year overall survival of $89 \%$, meanwhile, those who require a total laringectomy due to a more aggressive tumour behaviour; the overall survival decrease to $50 \%$. Obviously, patients with early stages show, not only, a better survival rate, also a better functional larynx preservation.

Sinclair et al.$^{[18]}$ demonstrated that intelligible speech could be preserved in $66-71 \%$ of patients in which conservative larynx therapies were performed. It supposes a better QOL in this group of patients. ${ }^{[18]}$

Oral recurrences are easier to detect, but the prognosis is poorer than other location, probably the reason is the different lymphatic drainage pathways, biological behaviour and the easy dissemination to many other areas of the oral cavity.

In contrast to laryngeal recurrences, the oral cavity recurrence occurs more frequently in distant sites. According to some studies, one of the determinant prognostic factor for long 
disease-free survival is the tumour depth more than $10 \mathrm{~mm}$ and presence of neck metastases. ${ }^{[19]}$ Regarding the group of patients with recurrences after a long period of time free of disease, the overall survival rate is higher in the group where salvage surgery were performed than the group who receive RT/CMT ( $84 \%$ vs. 52\% after 5 years).

Analysing the group of patients who presented a short period of free survival disease (FSD), the different survival after 5 years was lower, $38 \%$ vs. $31 \%$; this result could be caused by an early recurrence and infiltrative feature of the tumour, which determine a more aggressive behaviour that hides an occult expansion more difficult to be eradicated. In conclusion, a short period of FSD is a negative prognosis factor. ${ }^{[2,21]}$

Oropharyngeal recurrences are more common despite the prevalence of HPV andits high sensitivity to CMT/RT. The rates of regional and distant failure in patients with HPV+ disease were $14 \%$ and $9 \%$ respectively in the Radiation Therapy

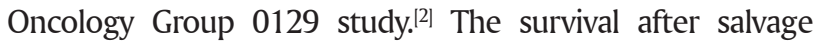
surgery in recurrence cases is worse than for larynx and oral cavity neoplasms with a 5-year survivor of $13-28 \%$.

The salvage surgery or reirradiation in oropharynx often results in high comorbidity including dysphagia, aspiration, dysarthria and permanent tracheostomy. The development of microsurgical reconstruction has led the possibility to perform salvage surgical treatment in more cases although the functional and QOL worsening are more controversial.

Many authors referred that the time needed to return to overall baseline health after a free flap reconstruction exceed the mean time of FSD before a second recurrence, despite the controversies, it is obvious that microvascular reconstruction demonstrates to be feasible and reliable, with low rate of complications and a better impact on patients. ${ }^{[22]}$ As well as in other tumours in oral cavity, the FSD until recurrence is one of the most important prognostic factor. Nevertheless, in that cases, salvage surgery whenever is possible, demonstrates to be more effective than RT/CMT, despite the functional sequelae.

Recurrences in hypopharynx show worse survival and functional results than other location. Symptoms may be non-specific and diagnosis can be delayed when the disease is already advanced.

Lymphatic spread is extensive and invasion of unresectable structures can be affected, Salvage surgery such as pharyngo-laringectomy has dramatic side effects and a high risk of postoperative complications. About 29\% of patients present resectable recurrences at the moment of diagnosis, maybe this situation determine that a few cases could obtain benefits from salvage surgery.

Nevertheless, when surgery is possible, has demonstrated it is the best option to control de tumour. Some studies, showed how salvage surgery gets the same survival rates in patients previously treated with RT/CMT than patients who surgical treatment where done.

Regional recurrence is another bad prognosis factor, as well as the presence of distant metastasis. Even if, isolated neck nodule is ease to be resected compared to local recurrence, patients with regional recurrences have better free tumour margin control at the surgical moment (42\% vs. 29\%) rather than local recurrences. But, present a worse long term survival (26\% vs. $42 \%)$. Also, overall survival decreases in operated necks than others where surgery was not performed (18\% vs. 32\%). ${ }^{[23]}$ Lim et al. ${ }^{[24]}$ found in rN2-rN3 stages that previous neck dissection and previous RT/CMT are the worst negative predictive factors.

\section{RESULTS CONCERNING QOL}

According to the World Health Organization, health-related quality of life (HRQOL) is defined as the self-perception of

Table 1: Commonly used tools to collect patient-reported QOL outcomes in patients with HNSCC

\begin{tabular}{lc}
\hline $\begin{array}{l}\text { QOL instrument-specific measures } \\
\text { for head and neck cáncer }\end{array}$ & Description \\
\hline EORTC QOL Head and Neck Version & $\begin{array}{c}\text { 35-item, self-administered questionnaire to } \\
\text { be administered along with EORTC QLQ-30 } \\
\text { (EORTC QLQ-H\%N35) }\end{array}$ \\
$\begin{array}{l}\text { Functional Assessment of Cancer } \\
\text { Therapy-Head and Neck (FACT-H\%N) }\end{array}$ & $\begin{array}{c}\text { 12 questions specific to head and neck } \\
\text { cáncer }\end{array}$ \\
$\begin{array}{l}\text { FACT-Head \& Neck Symptom Index } \\
\text { (FHNSI) }\end{array}$ & $\begin{array}{r}\text { 10-item, self-administered questionnaire, a } \\
\text { subset of the FACT-H\&N }\end{array}$
\end{tabular}
(FHNSI)

\section{Liverpool Oral Rehabilitation Questionnaire}

MD Anderson Dysphagia Inventory (MDADI)

The University of Washington Quality of 10 domains, self-administered questionnaire Life Instrument (UW-QOL) 40-item, self-administered questionnaire

20-item self-administered questionnaire for patients with head and neck cáncer

Pain, appearance, activity, recreation, swallowing, chewing, speech, shoulder problems, taste, saliva and general health questions 
patients in the cultural context and valuable systems where they live in relation with their expectations, standards and concerns.

HRQOL is the assessment of the effect of a disease or treatment of a patient's wellbeing and daily function. ${ }^{[25}$ It is a multidimensional tool reflecting the self-perception of the patients.

Evaluating the HRQOL of patients can be a helpful tool for physicians before taking decisions about the effectiveness of treatments, clarifying and helping to decide according to the side effects, can be used as a prognostic factor to analyse symptoms and evolution, identifying factors which can interfere the survival of patients, useful to estimate cost-effectively of therapies, helping to organize and maintain the quality of therapies. It helps to develop new drugs and reveal patients priorities. ${ }^{[26]}$

There are amounts of questionnaires used to determine the impact of cancer or treatments on patients. In contrast, just a few other surveys are designed specifically for patients with HNSCC [Table 1].

In our daily practice is common ask to the patient about how they feel but we do not usually spend time in complete questionnaires unless for some specific researches. Complete a survey means leave the patient alone in a proper environment without the influence of distractors to avoid bias or incorrect results. Many authors tried to solve the problem making online questionnaires, by this way we do not miss time and we let the patient a comfortable moment to do the questionnaire and value how the cancer affects them daily.

Specifically, patients' concerns about HNSCC can depend on individual factors such as age, comorbidity and psychosocial situation, stage and side effects. Motorization of the QOL can be a value tool to measure effectiveness of the treatment like how determine the intensity of chemotherapy. Information obtained from questionnaires could be useful to make decisions and management of patients, give priority to some important factors for their life such as pain, organ preservation, speech, physical appearance and their worries about recurrences.

The term QOL includes many factors related with life conditions, subjective reflection about the individual well-being rate. During the last years, a lot of studies have been published about QOL, which is consequence of the great response to the treatment. Professionals must be concerned not only about surgery, therapeutic treatment and complication rate, also about psychosocial aspect of people. For many authors QOL is an independent survival factor. ${ }^{[27,28]}$ Due to the subjectivity of the term and how difficult is to measure, value the QOL is challenging, that is why many questionnaires have been developed.

There are many questionnaires in the literature, such as number of surveys just reflects that any of them is well validated, there are not common criteria, but all of them must be easy to understand and quickly to complete in no more than $10 \mathrm{~min}$.

One of them is the University of Washington Quality of Life (UW-QOL), this questionnaire is short and easy to response and has been validated in many studies published. It includes 12 domains: pain, appearance, activity, recreation, swallowing, chewing, speech, shoulder, taste, saliva, mood and anxiety. This questionnaire also added final global question where the patient could explain which factors secondary to the tumour affected mostly in their daily activity giving them the chance to add several aspects not asked before. Each domain has 5 possible answers, with the score ranging from 0 (worst) to 100 (best). ${ }^{[29]}$

Some of the disadvantages that we find is due to most of studies are retrospective, and there are just a few prospective results. Visacri et al. ${ }^{[30]}$ elaborated a study including prospectively 32 patients who underwent RT/CMT and they evaluated the quality of life using UW-QOL questionnaire. There was a reduction in overall QOL that was significant after cycle 2 of chemotherapy and the sixth week of radiotherapy when compared with baseline. There was a significant improvement in some domains, such as pain and anxiety. The domain most affected after the start of treatment was taste. ${ }^{[30}$

Another study analysed the QOL in a group including 82 patients who completed the EORTC QLQ-H\%N35 questionnaire in 4 different times: before starting the radiotherapy, in the middle (15th or 20th fraction the radiotherapy), at the end, at 1 month and at 6 months after the treatment. In the middle, at the end the radiotherapy, one and six-month after the treatment, compared to before starting the radiotherapy, all symptom scales of the quality of life were affected negatively. However, 6 months after radiotherapy, all of them show an improvement excepting, dental problems, dryness of the mouth and the viscosity of the saliva. According to the localization, stickiness of saliva and dry mouth were significantly more frequent in the tumours of the nasopharynx, the oral cavity and the oropharynx, compared to the tumours of the larynx area. Regarding age, groups over 65 years demonstrated better results than young people. Also, the group with high radiation was affected more in terms of shortage of social interaction, speech problems, eating in social environment, opening the mouth, sticky saliva, feeling sick, weight loss and additional nutrient intake. ${ }^{[31]}$

Qiu et al. ${ }^{[29]}$ compared the impact in QOL of patients with HNSCC treated with surgery and adjuvant therapies versus those treated with radical RT alone. A total of 30 patients fulfilled the UW-QOL questionnaire at least after 1 year of follow up. According to the results, pain due to treatment recreation activities and shoulder weakness were well tolerated by most patients. But, chewing and taste were the domains with the worst scores in both groups. Significant 


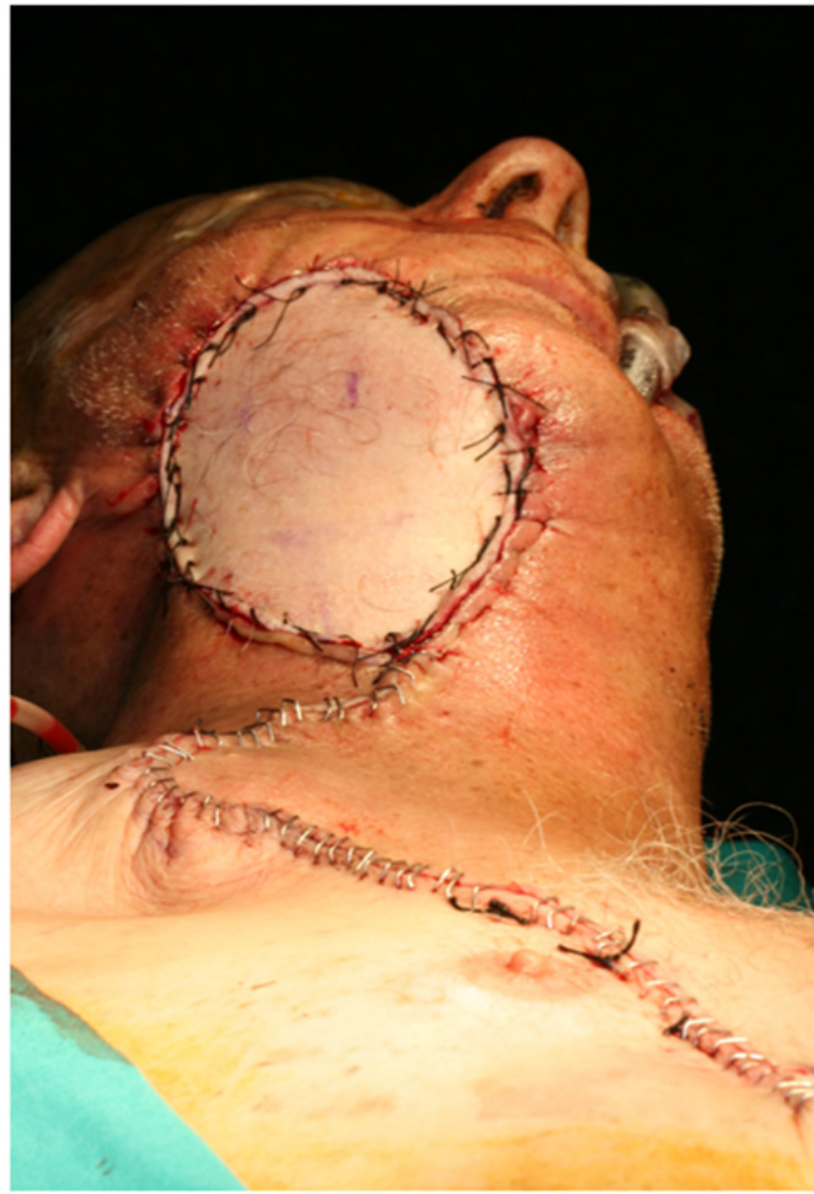

Figure 2: The reconstruction of mandibular oral squamous cell carcinoma with composite resection by the miocutaneous pectoralis major flap. Note differences in terms of color and possibility for scar contraction in the neck area

differences were found in the domains: appearance, shoulder and anxiety. Patients who underwent surgery and reconstruction were found to be more concerned about their appearance and complained about shoulder pain; whereas patients who were treated with radical radiotherapy were more anxious about their cancer. Finally, no significant differences were found according to the follow-up, it seems that do not interfere in the QOL.[29]

Chewing is the function that was mostly impaired after HNSCC treatment, despite the location. Also, impaired chewing may lead to dysphagia and insufficient feeding. These are consequences not only of radiation and surgical damage of the salivary glands but also his disruption of the normal anatomy of the jaw. Thus, all efforts must be made to preserve vital structures and organ-function, the use of organ-sparing RT could be a good option because it predicts potential complications according to the dose of radiation and allows preservation of contralateral salivary glands. ${ }^{[32,33]}$

The facial disfigurement after surgery is considered to be the most distressing aspect of HNSCC, although is well tolerated in patients who received RT. The surgery group, scars and the different colour of the flaps' skin paddle add serious discomfort to patients [Figure 2]. Another aspect to be concerned is that anxiety was significantly higher in the group of radiotherapy, especially in women. ${ }^{[29]}$

Among psychosocial issues, depression is the most prevalent in cancer patients, and it is the most common reason for referral to a mental health professional in oncology. In head and neck cancer, depression rates can reach $43 \%$ before treatment and $44 \%$ after treatment, which is particularly elevated compared with all oncology patients, in whom depression rates vary between 20 and $30 \%$ at any one time. ${ }^{[34]}$

Depression is underdiagnosed and the consequence includes impaired quality of life, treatment noncompliance, and increased length of hospital stay, greater health care utilization, and suicide. Taking into account that HNSCC survivors rank among the top three cancers with the highest rates of suicide, after lung and stomach cancer, the main interest about target depression as a main QOL-outcome is the powerful to be prevented or treated using psychotherapy and/or pharmacologic therapy. ${ }^{[35,36]}$

Moubayed et al. ${ }^{[37]}$ established a study including 209 patients with HNSCC and they analysed the results of a few questionnaires to determine the presence of depression and its impact in their quality of life. They identified 4 independent predictors of long-term depressive symptoms after controlling for all patient, tumour and treatment factors. They include the following pre-treatment factors: (1) having more than 3 medications; (2) smoking at diagnosis; (3) having more than 14 drinks per week; and (4) T3 or T4 tumour stages. These factors were used as independent risk factors in the creation of a depression predictive score, identify patients at risk for developing depressive symptoms and to be treated. In this study, they conclude that in presence of 2 risk factors, there is $82.3 \%$ of probability to identify depressive symptoms. ${ }^{[37]}$

The development of new surgical techniques such as transoral robotic surgery (TORS) has let us to find not only the reduction of side effect; whereas it has demonstrated the same long-term results with better preservation of the quality of life. Choby et al. ${ }^{[38]}$ analysed in a retrospective study 34 patients who TORS was performed in oropharynx (tonsil and base of the tongue). They used the UW-QOL questionnaire in different times: at 1-month, 6-month, 12-month and 24-month postoperative visits. The results showed a tendency to improve throughout follow-up, specially the domains pain, swallowing, activity and chewing. Increasing recognition of the adverse effects of CRT and their negative effect on QOL has provided the rationale for TORS as a primary treatment modality option for some head and neck cancers. This study not only obtained an improvement in the QOL, whereas presents better results compared to the group of conventional surgery. ${ }^{[38]}$

Other authors analysed 32 patients classified in 3 groups: surgery for resection, surgery and adjuvant RT and surgery and adjuvant RT/CMT. In this case, they apply the 
UW-QOL modified questionnaire in which it is included a new item called overall well-being. Results showed that scores for all parameters were higher or at least equally high for group 2 compared to group 1 . When asked to compare their pre- and post-therapeutic HRQOL, $21.9 \%$ of patients in group 1 stated that there were no differences, whereas $46.9 \%$ stated there was a moderate deterioration, and $31.3 \%$ stated that deterioration was marked. Furthermore, 53.1\% of patients in group 2 and $56.3 \%$ of patients in group 3 reported a marked deterioration of their QOL after treatment. In fact, just $34,4 \%$ in group 2 and $53.1 \%$ in group 3 would consent to further RT/CMT if necessary during the follow up. ${ }^{[3]}$

Herce-Lopez et al. ${ }^{[40]}$ elaborated a cross-sectional study including 60 patients treated for a head and neck cancer who survived over 5 years without recurrences. In this case, patients filled out the SF-36 questionnaire, which include 8 categories: physical functioning, role-physical, role-emotional, vitality, mental health, social function, pain and the social dimension. Regarding the impact of gender, in the male group, found statistically significant positive differences for the dimensions of vitality and general health; and significantly negative for the dimensions of role-physical, social functioning and pain. In the female group, statistically significant negative differences for the dimensions social functioning were observed. Respecting age, patients over 65 years showed statistically significant negative differences for social functioning and pain; and positive for vitality and general health status. Similar to previous results, T1-T2 stages had significant positive differences for general health and negative for role-physical, role-emotional, social functioning and paint. Also, T3-T4 showed statistically negative differences for social functioning and pain. The impact of surgical reconstruction showed that patients who underwent complex reconstruction referred worse social functioning and pain, whereas patients who did not receive this kind of surgical procedure they referred a better general health status unless worst role-physical, role-emotional, social functioning and pain. ${ }^{[40]}$

Follow up length is still a controversial aspect, because every author obtained results according a short follow-up period. Nevertheless, Rogers et al. ${ }^{[41]}$ determined no differences respecting the QOL between patients after 1 year of treatment or 5 years. Although, other authors are not agree with this because patients consider themselves cured 5 years after treatment may significantly change their perception of the disease.

With regard to survival prediction from pre-treatment HRQOL data among HNSCC patients, few investigations with some extent of varied finding have been published. A significant predictive effect of HRQOL scores on survival has been detected, but noteworthy variations with regard to design, simple sizes, and use of HRQOL inventories exist. ${ }^{[42-44]}$ Osthus et al. ${ }^{[45]}$ determined the predictive potential of HQROL scores in a heterogeneous cohort of patients with newly diagnosed HNSCC. They used QLQ-C30 and QLQh\&N35 questionnaires in a group of 106 patients, finding that high comorbidity is a risk factor especially cardiac disease. They did not find relation between tumour stage and tumour location, and, alcohol consumption supposes a predictive value of survival. ${ }^{[45]}$

\section{CONCLUSION}

Over the last decades, the perspective and management of SCC in head and neck has changed, many disciplines have contributed to improve the prognosis not only surgeons. The advancement of reconstructive surgical techniques and adjuvant therapies such as RT/CMT made treatable an increased number of patients with many risk factors that otherwise would have been relegated to palliative care.

Regarding SCC prognosis, many factors have demonstrated to be influential but, high level tumour stage and short length of free survival disease time are the most important to predict the really expectation of therapies.

Despite de numerous studies published in the literature about the assessment of the quality of life in patients with HNSCC, the heterogeneity of the population and the lack of internal validity of studies, can explain why there is not a consensus about the accuracy of the questionnaires as a predictive tool to distinguish the bad prognosis cases and their capacity to choose the best therapeutic option in every situation.

Currently, data do not let us individualize patients' treatment, but this is the objective for the future and maybe new studies will show us the ways to identify how the QOL can modify the treatment choices.

\section{Financial support and sponsorship \\ Nil.}

\section{Conflicts of interest}

There are no conflicts of interest.

\section{REFERENCES}

I. Machiels JP, Lambrecht M, Hanin FX, Duprez T, Gregoire V, Schmitz S, Hamoir M.Advances in the management of squamous cell carcinoma of the head and neck. FI000Prime Rep 2014;6:44.

2. Ang KK, Harris J, Wheeler R, Weber R, Rosenthal DI, Nguyen-Tân PF, Westra WH, Chung CH, Jordan RC, Lu C, Kim H, Axelrod R, Silverman CC, Redmond KP, Gillison ML. Human papillomavirus and survival of patients with oropharyngeal cancer. N Engl J Med 2010;363:24-35.

3. Gillison ML. Human papillomavirus-associated head and neck cancer is a distinct epidemiologic, clinical, and molecular entity. Semin Oncol 2004:31:744-54.

4. Johnson-Obaseki S, McDonald JT, Corsten M, Rourke R. Head and neck cancer in Canada: trends 1992 to 2007. Otolaryngol Head Neck Surg 2012; 147:74-8.

5. Checcoli E, Bianchini C, Ciorba A, Candiani M, Riberti C, Pelucchi S, Pastore A. Reconstructive head and neck surgery: oncological and functional results. Tumori 2013; 99:493-9.

6. Gregoire V, Lefebvre JL, Licitra L, Felip E; EHNS-ESMO-ESTRO Guidelines Working Group. Squamous cell carcinoma of the head and 
neck: EHNS-ESMO-ESTRO clinical practice guidelines for diagnosis, treatment and follow-up. Ann Oncol 2010;21:v184-6.

7. Miglani A, Patel VM, Stern CS, Weichman KE, Haigentz M Jr, Ow TJ, Garfein ES. Palliative reconstruction for the management of incurable head and neck cancer.J Reconstr Microsurg 2016;32:226-32.

8. Morris LG, Sikora AG, Patel SG, Hayes RB, Ganly I. Second primary cancers after an index head and neck cancer: subsite-specific trends in the era of human papillomavirus-associated oropharyngeal cancer. J Clin Oncol 20I I;29:739-46.

9. Peck BW, Dahlstrom KR, Gan SJ, Caywood W, Li G, Wei Q, Zafereo $M E$, Sturgis EM. Low risk of second primary malignancies among never smokers with human papilloma virus-associated index oropharyngeal cancers. Head Neck 2013;35:794-9.

10. van der Laan BF, Baris G, Gregor RT, Hilgers FJ, Balm AJ. Radiationinduced tumours of the head and neck.J Laryngol Otol 1995; 109:346-9.

II. Zbaren P, Nuyens M, Curschmann J, Stauffer E. Histologic characteristics and tumor spread of recurrent glottic carcinoma: analysis on wholeorgan sections and comparison with tumor spread of primary glottic carcinomas. Head Neck 2007;29:26-32.

12. Colevas AD. Chemotherapy options for patients with metastatic or recurrent squamous cell carcinoma of the head and neck. J Clin Oncol 2006;24:2644-52.

13. Fury MG, Pfister DG. Current recommendations for systemic therapy of recurrent and/or metastatic head and neck squamous cell cancer. J Natl Compr Canc Netw 201 I; 9:681-9.

14. Goodwin WJ, Jr. Salvage surgery for patients with recurrent squamous cell carcinoma of the upper aerodigestive tract: when do the ends justify the means? Laryngoscope 2000; 1 10:1-18.

15. Stell PM. Time to recurrence of squamous cell carcinoma of the head and neck. Head Neck 1991;13:277-81.

16. Holsinger FC, Funk E, Roberts DB, Diaz EM Jr. Conservation laryngeal surgery versus total laryngectomy for radiation failure in laryngeal cancer. Head Neck 2006;28:779-84.

17. Ganly I, Patel SG, Matsuo J, Singh B, Kraus DH, Boyle JO,Wong RJ, Shaha $A R$, Lee N, Shah JP. Results of surgical salvage after failure of definitive radiation therapy for early-stage squamous cell carcinoma of the glottic larynx. Arch Otolaryngol Head Neck Surg 2006; 132:59-66.

18. Sinclair CF, Rosenthal EL, McColloch NL, Magnuson JS, Desmond RA, Peters GE, Carroll WR. Primary versus delayed tracheoesophageal puncture for laryngopharyngectomy with free flap reconstruction. Laryngoscope 2011;121:1436-40.

19. Liao CT, Chang JT,Wang HM, Ng SH, Hsueh C, Lee LY, Lin CH, Chen IH, Huang SF, Cheng AJ, Yen TC. Salvage therapy in relapsed squamous cell carcinoma of the oral cavity: how and when? Cancer 2008; I 2:94-103.

20. Mucke T, Wagenpfeil S, Kesting MR, Holzle F, Wolff KD. Recurrence interval affects survival after local relapse of oral cancer. Oral Oncol 2009;45:687-91.

21. Liu SA, Wong YK, Lin JC, Poon CK, Tung KC, Tsai WC. Impact of recurrence interval on survival of oral cavity squamous cell carcinoma patients after local relapse. Otolaryngol Head Neck Surg 2007; 1 36: I I 2-8.

22. Kostrzewa JP, LancasterWP, IseliTA, Desmond RA, CarrollWR, Rosenthal EL. Outcomes of salvage surgery with free flap reconstruction for recurrent oral and oropharyngeal cancer. Laryngoscope 2010;120:267. 72.

23. Wong LY,Wei WI, Lam LK, Yuen AP. Salvage of recurrent head and neck squamous cell carcinoma after primary curative surgery. Head Neck 2003;25:953-9.

24. Lim JY, Lim YC, Kim SH, Byeon HK, Choi EC. Factors predictive of successful outcome following salvage treatment of isolated neck recurrences. Otolaryngol Head Neck Surg 2010; 142:832-7.

25. Licitra L, Mesia R, Keilholz U. Individualised quality of life as a measure to guide treatment choices in squamous cell carcinoma of the head and neck. Oral Oncol 2016;52:18-23.

26. Moriel G, Roscani MG, Matsubara LS, Cerqueira AT, Matsubara BB. Quality of life in patients with severe and stable coronary atherosclerotic disease. Arq Bras Cardiol 201 0;95:691-7.

27. Goldstein DP, Hynds Karnell L, Christensen AJ, Funk GF. Health-related quality of life profiles based on survivorship status for head and neck cancer patients. Head Neck 2007;29:22I-9.

28. Hammerlid E, Wirblad B, Sandin C, Mercke C, Edström S, Kaasa S, Sullivan M,Westin T. Malnutrition and food intake in relation to quality of life in head and neck cancer patients. Head Neck 1998;20:540-8.

29. Qiu SS, Cambeiro M, Hontanilla B. Comparison of quality of life in head and neck stage IV squamous cell cancer patients treated with surgery and reconstruction versus radical radiotherapy. Ann Plast Surg 20। 4; 73:205-9.

30. Visacri MB, Ferrari GB, Dias P, Pimentel R, de Souza CM, Costa AP, de Carvalho Pincinato E, Lima CS, Mazzola PG, Moriel P. Quality of life of patients with squamous cell carcinoma of the head and neck receiving high-dose cisplatin chemotherapy and radiotherapy. South Med J 2015; 108:343-9.

31. Akkas EA, Yucel B, Kilickap S, Altuntas EE. Evaluation of quality of life in Turkish patients with head and neck cancer. Asian Pac J Cancer Prev 20।3; 14:4805-9.

32. Rogers S, Lowe D.Screening for dysfunction to promote multidisciplinary intervention by using the University of Washington Quality of Life questionnaire. Arch Otolaryngol Head Neck Surg 2009; 135:369-75.

33. Dirix $P$, Nuyts $S$. Evidence-based organ-sparing radiotherapy in head and neck cancer. Lancet Oncol 20 10; I :85-91.

34. Haisfield-Wolfe ME, McGuire DB, Soeken K, Geiger-Brown J, De Forge $B R$. Prevalence and correlates of depression among patients with head and neck cancer:a systematic review of implications for research. Oncol Nurs Forum 2009;36:E107-25.

35. Misono S, Weiss NS, Fann JR, Redman M, Yueh B. Incidence of suicide in persons with cancer.J Clin Oncol 2008;26:473I-8.

36. Kendal WS. Suicide and cancer: a gender-comparative study. Ann Oncol 2007;18:381-7.

37. Moubayed SP, Sampalis JS, Ayad T, Guertin L, Bissada E, Gologan OE, Soulières D, Lambert L, Filion E, Nguyen-Tan PF, Christopoulos A. Predicting depression and quality of life among long-term head and neck cancer survivors. Otolaryngol Head Neck Surg 2015;152:91-7.

38. Choby GW, Kim J, Ling DC, Abberbock S, Mandal R, Kim S, Ferris RL, Duvvuri U. Transoral robotic surgery alone for oropharyngeal cancer: quality-of-life outcomes. JAMA Otolaryngol Head Neck Surg 2015;141:499-504.

39. Mucke T, Koschinski J, Wolff KD, Kanatas A, Mitchell DA, Loeffelbein DJ, Deppe H, Rau A. Quality of life after different oncologic interventions in head and neck cancer patients. J Craniomaxillofac Surg 2015;43:1895-8.

40. Herce-Lopez J, Rollon-Mayordomo A, Lozano-Rosado R, InfanteCossio P, Salazar-Fernandez Cl. Assessment of quality of life of oral cancer survivors compared with Spanish population norms. Int J Oral Maxillofac Surg 2013;42:446-52.

4I. Rogers SN, Hannah L, Lowe D, Magennis P.Quality of life 5-10 years after primary surgery for oral and oro-pharyngeal cancer.J Craniomaxillofac Surg 1999;27:|87-91.

42. Montazeri A. Quality of life data as prognostic indicators of survival in cancer patients: an overview of the literature from 1982 to 2008 . Health Qual Life Outcomes 2009;7:102.

43. Grignon LM, Jameson MJ, Karnell LH, Christensen AJ, Funk GF. General health measures and long-term survival in patients with head and neck cancer. Arch Otolaryngol Head Neck Surg 2007;133:47 I-6.

44. Meyer F, Fortin A, Gelinas M, Nabid A, Brochet F, Têtu B, Bairati I. Health-related quality of life as a survival predictor for patients with localized head and neck cancer treated with radiation therapy. J Clin Oncol 2009;27:2970-6.

45. Osthus AA, Aarstad AK, Olofsson J, Aarstad HJ. Prediction of survival by pretreatment health-related quality-of-life scores in a prospective cohort of patients with head and neck squamous cell carcinoma.JAMA Otolaryngol Head Neck Surg 2013;139:14-20. 